\title{
ESCOLA SEM PARTIDO: TEMPO SOMBRIO PARA A EDUCAÇÃO PÚBLICA, LAICA E UNIVERSAL
}

\section{ARTIGO ORIGINAL}

MORAES, Vitor de ${ }^{1}$

MORAES, Vitor de. Escola Sem Partido: Tempo sombrio para a Educação Pública, laica e universal. Revista Científica Multidisciplinar Núcleo do Conhecimento. Ano 05, Ed. 10, Vol. 20, pp. 05-20. Outubro de 2020. ISSN: 24480959, Link de acesso: https://www.nucleodoconhecimento.com.br/educacao/escolasem-partido

\section{RESUMO}

O referido artigo tem por objetivo analisar, o que chamaremos (grifo nosso), de Projeto Ideológico Escola Sem Partido (PESP). Evidenciando suas múltiplas dimensões e intencionalidades, analisando as contradições presentes nos discursos, a favor e contra, e o que podemos extrair dessas contradições. Para tal, na análise foi utilizado um referencial teórico de intelectuais que estudam o tema, para assim podermos observar ideologias favoráveis e contrárias ao projeto. Utilizamos fontes midiáticas, como o site dos idealizadores do PESP e em diferentes meios midiáticos. A pesquisa ancorou-se junto aos meios de comunicação, eletrônicos e impressos, websites e redes sociais vinculadas ao PASP, e abordagens críticas, da análise criteriosa do discurso dos idealizados do PASP. Buscou-se de forma didática apresentar o Projeto Escola Sem Partido como ele é apresentado e dirigido para a sociedade, trazendo à tona sua ideologia e seu partido. As análises evidenciaram que o Projeto Escola Sem Partido tem sua ideologia e seu partido cunhados em princípios, bem tangíveis, como: o conservadorismo, o fanatismo religioso, a negação da ciência, o neoliberalismo

\footnotetext{
${ }^{1}$ Mestre em Geografia - UNESP/SP. Mestre em Educação pela UNICENTRO PR, Especialista em Educação do Campo pela UFPR, Especialista em Educação Matemática pela UNICENTRO - PR.
} 
econômico, a desqualificação dos docentes, deslegitimação da autonomia docente e a supressão da escola pública, laica e universal.

Palavras-chave: Escola Sem Partido, educação, ideologia.

\section{INTRODUÇÃO}

Ao analisarmos o projeto denominado de Escola Sem Partido (PESP), nos deparamos com um projeto educacional tangível, no sentido universal educacional de pensar a educação como um todo, no seu âmago, porém, com princípios extremamente definidos os quais serão evidenciados e detalhados posteriormente neste trabalho.

Quanto ao método, metodologia e técnicas, utilizados para desenvolver a analise deste trabalho, utilizamos, Saviani (2020), que vai no cerne da intencionalidade desse projeto, "O referido projeto é chamado por seus críticos de "lei da mordaça", pois explicita uma série de restrições ao exercício docente negando o princípio da autonomia didática consagrado na legislação e nas normas relativas ao funcionamento do ensino. Moreira (2016) que traz à tona a ideologia do PASP "Ao naturalizar desigualdade e opressão e pretender aulas neutras, projeto em exame no MEC busca silenciar vozes e criar espaços de conformismo e resignação às injustiças", Frigotto (2016), que analisa a concepção desse movimento, "O movimento Escola sem Partido se auto identifica como uma iniciativa conjunta de estudantes, pais e professores articulados para ações e estratégias de combate a um suposto quadro de contaminação político-ideológica" e o material empírico do site da Escola sem Partido[2], além de materiais de revistas, entrevistas e artigos do movimento. Consideramos que se trata de fontes de caráter documental, que podem ser classificadas como secundárias. As fontes da análise documental constituem conhecimento, dados ou informações já reunidos ou organizados. Não podemos negligenciar a análise dos discursos e suas intencionalidades por disputa de espaço e de poder. Para Foucault (1998) "são disputas por poder e dominação, pois carregam tais intencionalidades, independentemente do Estado". 
Na visão dos ideólogos do PESP, a educação e a escola, objeto de desejo deles, é subdividida em quatros grandes áreas: a) o professor como intelectual orgânico ideológico de esquerda; b) os materiais didáticos como instrumentos teóricos, epistemológicos, antológicos, da esquerda; c) o espaço escolar como o espaço para a organização e cooptação dos estudantes para serem militantes de esquerda; e d) o tempo escolar utilizado para preparar o exército vermelho.

Evidenciamos essa subdivisão ao realizar a análise do discurso do PESP, discurso esse presente permanentemente na mídia. Não constatamos, no decorrer das análises, receio ou timidez, por parte dos ideólogos do PESP e de seus apoiadores, em expor pensamentos considerados de cunho arcaico, conservador, anticiência, antieducação, contra o ensino laico, contra a pluralidade de ideias, salientamos ainda, que estes usam do discurso de que suas ideias estão pautadas e respaldadas pela constituição, o que consideramos um equívoco proposital, pois não são ignorantes da lei, apesar de desconhecerem a ciência educacional.

Os discursos são baseados na conjuntura política de ideais da direita, ou seja, pautados nos interesses da classe alta. Lembramos que a elite sempre teve acesso as benesses do Estado, sempre estiveram presentes na estrutura governamental. Todavia, essa elite, após a atuação de um governo populista, se vê rodeada por aqueles considerados sempre como subalternos, os pobres e trabalhadores. Essa camada da população brasileira passou a ocupar espaços antes ocupados somente pela elite, seja lecionando, estudando ou dirigindo a educação em muitos espaços.

Essa inserção e/ou transição entre as camadas sociais, causou incômodo nessa elite de direita, que mesmo sem formação em educação, ensino ou escola veem propor algo completamente descontextualizado da realidade vivenciada nas escolas brasileiras. As justificativas dos intelectuais do PASP são pautadas em fatos isolados e as colocam como se fossem a prática dos espaços escolares. O PASP não questiona a invasão do capitalismo na formação escolar estritamente voltada para o mercado, formação que fragiliza o sistema escolar pois apenas forma e oferta os indivíduos para o mercado de trabalho. Ideal contrário ao da formação escolar que se pretende, voltada para o sujeito, com uma formação ampla, humana e integral. 
Para tal, levantamos aqui o seguinte questionamento: Qual a impossibilidade, se tratando de um país tão diverso, se pensar uma educação neutra e para todos? Decorre que o próprio conceito da educação está intercalado aos conceitos de liberdade e de democracia, concomitantemente ao direito da aquisição de diferentes saberes. Cabe a educação, enquanto instituição escolar, abordar temáticas que proporcionem aos alunos, enquanto sujeitos, conhecer as diferenças, possibilitando a estes conviver com culturas diferentes, pensamentos diferentes, sociedades diferentes, religiões diferentes, simbologias e imaginários populares diferentes.

A escola é o espaço criado para que ocorra o processo de ensino-aprendizagem na inter-relação do educador-educando em que não é possível retirar dessa formação a ética, a criticidade, a educação plena, para que assim o indivíduo seja capaz de fazer escolhas em sua vida. Portanto, ao afirmar que a escola não é espaço onde deve-se ocorrer debates, onde deve-se conhecer o outro e sua cultura, onde o diálogo não possa ocorrer de forma aberta e livre, estamos afirmando o discurso do PASP, que sem pretender ou pretendendo evidencia que se trata de um projeto ideológico de opressão e subalternidade das camadas menos favorecidas da sociedade brasileira.

que deveríamos, enquanto governo e governantes, estar debatendo é a consolidação do compromisso ético escolar, que tem por base proporcionar aos estudantes todas as possibilidades de aprendizagens, para que assim possam estruturar suas escolhas no decorrer da vida. O que o PASP reproduz em seus discursos vai contra a consolidação das leis e direitos estudantis garantidos em um longo processo de luta no decorrer da história brasileira. A consolidação do PASP nas escolas fortaleceria os discursos de ódio, o racismo, machismo, dentre outros aspectos brutais e violentos que se escondem por traz do discurso conservador e cristão. Podemos considerar um desastre em termos de pensar a ciência educacional enquanto igualdade de direitos e de humanidade.

Ao pensar sobre os efeitos da educação nas bases sociais deve-se levar em conta de que forma a escola pode contribuir na qualidade de vida das pessoas, sem colocar em risco sua autonomia, coletiva e individual, fortalecendo vínculos e possibilitando novas possibilidades de pensar e agir no mundo. Não estamos negando que a escola, 
enquanto instituição escolar pública, tem suas contradições e que ainda tem muito a avançar no que tange a qualidade, física e humana, de ensino. Porém, podemos afirmar que há muitos educadores engajados na luta pelos direitos dos educandos a uma educação livre e neutra, onde todos os discursos sejam respeitados e ouvidos. Existem muitos educadores que lutam, diariamente, contra todas as formas de injustiças.

Outro absurdo, se tratando da ideologia do PASP, é a convocação de estudantes responsáveis por vigiar os professores/educadores tidos como de esquerda, comunistas, etc, adjetivos usados pela direita para se referir a aqueles que vão contra seu pensamento. Entretanto, o PASP não tem propostas que visem a melhoria da qualidade ou da infraestrutura da escola, tão pouco debate sobre aspectos financeiros, bem como resguardar o financiamento estatal para dar conta de atender de forma qualitativa todos os estudantes, seja rural, urbano do centro ou da periferia.

A Constituição Federal de 1988, no artigo 206, inciso III, determina que a educação deve ser feita com base no "pluralismo de ideias e de concepções pedagógicas, e coexistência de instituições públicas e privadas de ensino", portanto, nestes termos legais questionamos, novamente, se é possível falar em uma educação neutra? Levantamos também outros questionamentos de afirmações que se fazem presentes no discurso do PASP: Em um país onde os dados de abuso e exploração infantil são alarmantes e, comprovadamente, ocorrem em sua maioria na família ou em torno dela, é possível pensar que a educação moral e sexual é somente dever da família? A introdução deste projeto de leira reduzir os confrontos ideológicos presentes nas escolas? Em que medida esse projeto criará um estado autônomo, laico, plural? Em que medida esse projeto constitui-se com um projeto de desenvolvimento educacional que priorize a diversidade, a pluralidade e a humanização? Dizer que será o fim de uma ideologia, a de esquerda, possibilita a leitura e compreensão de que outras ideologias podem ou poderão ser introduzidas nas escolas, de que os sujeitos não têm a liberdade de escolha e de pensamento. 


\section{A IDEOLOGIA DO PROJETO ESCOLA SEM PARTIDO (PASP)}

Louis Althusser (1971), define a ideologia como a relação imaginária dos indivíduos com suas condições reais de existência e, como descreve Michel Vovelle (1991), a ideologia é um conjunto de representações, mas também de práticas e comportamentos conscientes ou inconscientes. A ideologia aqui apresentada, pode ser entendida como um conjunto de ideias fundamentais que apresentam o pensamento de uma pessoa ou coletividade em um determinado período histórico. A ideologia, nesse sentido, tem por objetivo conservar ou transformar o sistema social, econômico, político ou cultural existente, portando, ela reflete sempre em projetos e programas políticos, e o estado além de cumprir deve exigir da sociedade que sempre cumpra tal ideia. As ideologias influenciam na educação, na sociedade, na economia, sendo, por isso, conhecidas como ideologias socioeconômicas, como a ideologia liberal clássica, neoliberal, comunista, capitalista, fascista, democrática, conversadora, anarquista, dentre outras. Nesse contexto surge o que denominam ser movimento, apresentados aqui neste trabalho como projeto, por ser idealizado não pelo movimento da sociedade civil, mas para atender um grupo organizado.

O movimento intitulado como Escola sem Partido surgiu em 2004, através da iniciativa de Miguel Nagib, então procurador do Estado de São Paulo. O projeto surgiu como uma reação a um suposto fenômeno de instrumentalização do ensino para fins político ideológicos, partidários e eleitorais, que em seu ponto de vista representam doutrinação e cerceamento da liberdade do estudante em aprender. Miguel Nagib apontava que muitos professores sob o pretexto de despertar a consciência crítica dos estudantes acabam deixando o processo educativo de lado em prol da disseminação de propaganda partidária e de ideais de esquerda. Em linhas gerais, o movimento reivindicaria a imparcialidade e a objetividade do professor em sala de aula alegando que, caso contrário, estaria sendo negado ao aluno o acesso a outras explicações e abordagens alternativas para os fenômenos estudados (PEREIRA, 2018).

Dentre as modificações solicitadas no ensino, o grupo tinha como um de seus fundamentos eliminar alguns princípios presentes na educação, tais como, a liberdade RC: 62417

Disponível em: https://www.nucleodoconhecimento.com.br/educacao/escola-sem-partido 
de cátedra do educador, além de mudar o protagonismo dos estudantes e influenciálos a serem "vigias" do estado, cuidando, observando e denunciando os educadores para o grupo do PASP.

No estudo dos materiais do site do PASP (2020), as propostas do PASP, permaneceram inativas até o ano de 2014, quando o Deputado Estadual do Rio de Janeiro, Flávio Bolsonaro, convidou o procurador Nagib para escrever um projeto de lei (PL 2974/2014) para ser apresentado à Assembleia Legislativa daquele Estado. No mesmo ano, o irmão do Deputado e vereador no Rio de Janeiro, Carlos Bolsonaro, lançou o PL 864/2014 para apreciação da Câmara Municipal. Como autor das propostas Miguel Nagib disponibilizou no site do movimento os dois projetos, municipal e estadual, e eles tem servido de inspiração para a disseminação de projetos do mesmo tipo em Câmaras Municipais e Assembleias Legislativas de vários Estados brasileiros: Rio Grande do Sul, Paraná, São Paulo, Espírito Santo, Goiás, Alagoas, Ceará, Amazonas e o Distrito Federal e Paraíba. O histórico de criação e implementação deixa claro e evidente que esse projeto foi conduzido por sujeitos políticos de direita com ideais conservadores e veementemente contra a esquerda.

No Estado de Alagoas a lei chegou a ser aprovada, mas acabou sendo contestada pela Advocacia Geral da União por considerar que o Estado estaria legislando em área de competência da União, especificamente no que tange ao artigo 206 da Constituição Federal onde é assegurada a pluralidade de ideias nos ambientes de Ensino (PEREIRA, 2018).

Para alguns estudiosos, como Pereira (2018), o projeto serve para a perseguição e censura ao docente. O que evidentemente tira do educador a condição ética, de caráter de ser um formador, passa a ser um profissional que atua de forma arbitrária e amedrontada, professar conteúdos que não permitam o questionamento, a curiosidade, algo tão imprescindível na vida escolar e humana.

Portanto, a grande polêmica em torno desses projetos seria a suposta perseguição e censura que se empreenderia junto ao trabalho docente, abrindo espaço inclusive para a perseguição política. Um dos pontos chave da proposta do PASP é a instalação 
de cartazes nos corredores e salas de aula elencando quais são os deveres do professor e o que não deve ser abordado em sala de aula. Na visão dos críticos ao projeto, ao se de impor limites ao trabalho do professor ele automaticamente deixaria de ser um mediador da aprendizagem e passaria a ser um mero transmissor de conteúdos disciplinares. Para os defensores do movimento, no entanto, a imparcialidade e a neutralidade em sala são fundamentais para que a formação do aluno ocorra sem influências ideológicas e partidárias, uma vez que toda ideologia atrapalha a compreensão da realidade e é dever do professor ensinar as coisas como realmente são independentemente de convicções pessoais (PEREIRA, 2018).O grupo que defende o PASP, tem como referência uma associação informal de pais, alunos e outro para divulgar e trabalhar o projeto junto a mídia, as coletividades de pais e aos governos.

O Movimento, Escola Sem Partido se divide em duas vertentes muito bem definidas, uma, que trabalha à luz do Projeto Escola Sem Partido, outra, o uma associação informal de pais, alunos e conselheiros preocupados com o grau de contaminação político-ideológica das escolas brasileiras, em todos os níveis: do ensino básico ao superior. A pretexto de transmitir aos alunos uma "visão crítica" da realidade, um exército organizado de militantes travestidos de professores prevalecese da liberdade de cátedra e da cortina de segredo das salas de aula para impingir-lhes a sua própria visão de mundo. Como membros da comunidade escolar - pais, alunos, educadores, contribuintes e consumidores de serviços educacionais -, não podemos aceitar esta situação. Entretanto, nossas tentativas de combatê-la por meios convencionais sempre esbarraram na dificuldade de provar os fatos e na incontornável recusa de nossos educadores e empresários do ensino em admitir a existência do problema. Ocorreu-nos, então, a ideia de divulgar testemunhos de alunos, vítimas desses falsos educadores. Abrir as cortinas e deixar a luz do sol entrar. Afinal, como disse certa vez um conhecido juiz da Suprema Corte dos Estados Unidos, "a littlesunlightisthebestdisinfectant”. Quando começávamos a pôr mãos à obra, tomamos conhecimento de que um grupo de pais e estudantes, nos EUA, movido por idêntica preocupação, já havia percorrido nosso caminho e atingido nossa meta: Noindoctrination.org. Inspirados nessa bem sucedida experiência, decidimos criar o EscolasemPartido.org, uma associação informal, independente, sem fins lucrativos e sem qualquer espécie de vinculação política, ideológica ou partidária. Miguel Nagib coordenador (ESCOLA SEM PARTIDO, 2020). 
$\mathrm{Na}$ citação, supracitada, do principal intelectual do projeto, fica evidente a vontade incontestável de tomar a escola para si e poder eliminar os professores de esquerda. Não se discute, educação, ensino, conhecimento, ciência educacional, porém o foco é a punição. Uma concepção, acerca dos profissionais da educação, de ódio o que beira a ideologia fascista. Para dar legitimidade ao discurso o grupo utiliza-se de vários argumentos, entre eles que os professores fazem um sequestro intelectual dos educandos, o que não é real, isso prova a empiria e ignorância dos membros do PASP.

De acordo como site $(G 1,2016)$, Fernando Penna, professor da Faculdade de Educação da Universidade Federal Fluminense (UFF) e um dos fundadores do grupo do PASP. No site do movimento, afirma que o professor não é educador, e sim transmissor de conhecimento. É representado como sequestrador intelectual. E os estudantes são folhas em branco, sem autonomia.

Outro elemento fundante que fica subentendido ou entendido, como afirma a antropóloga Yvonne Maggie, colunista do G1, acredita que a religião está por trás da questão, em um contexto de "extrema radicalização das ideias". Segundo ela, o projeto "quer proteger os estudantes e professores religiosos impedindo que os outros professores critiquem sua crença e exponham outras crenças. Escola sem Partido é um projeto que toca no debate entre laicidade, ideologia e religião nas escolas". Aqui neste trabalho tratamos a religião como ideologia e a laicidade como a necessária plenitude educativa para atingir o que demanda a LDB. Quando abrimos o site do Movimento Escola sem Partido nos deparamos com uma propaganda que já marca a posição ideológica e partidária do movimento.

O marketing utilizado para reforçar a ideia do movimento se pautava na premissa da existência de uma doutrinação no espaço escolar, sendo um dos slogans: "Diga não à doutrinação nas escolas e universidades. Junte-se ao Escola sem partido" (ESCOLA SEM PARTIDO, 2020). Atuando desde 2004, o Movimento Escola sem Partido é reconhecido nacionalmente como a mais importante e consistente iniciativa contra o uso das escolas e universidades para fins de propaganda ideológica, política e partidária. 
Evidenciamos, que as ideias defendidas pelo grupo do PASP são fundamentadas em oposição as ideologias do que eles têm por ideal de esquerda, de gênero, de uma escola laica e universal, o que já contrária uma constituição democrática, apesar da defesa eminente dos idealizadores do movimento de que a constituição pode e deve ser mudada e adaptada conforme a vontade dos adeptos do movimento, mesmo que seja um grupo e não represente a vontade do povo brasileiro.

Encontramos um link, no site do movimento, onde solicitavam ajuda financeira para avançarem no projeto, contudo, quando um grupo de esquerda solicita auxílio financeiro para alavancar seus projetos, é notório os questionamentos frente ao pedido de ajuda. Entretanto, neste caso está valendo, porque é para o movimento "deles" o "Escola sem partido". Encontramos no site também um link, onde apresentam a ideologia do movimento, seguido de um link para a divulgação/denuncia de possíveis casos do que eles chamam de doutrinação, em que eles destacam que as denúncias poderão se tornar públicas, porém descrevem que o sigilo será garantido, tanto por parte dos denunciantes como das vítimas, deixando em seguida um formulário "não obrigatório".

O autor da denúncia está ciente de que o Escola sem Partido poderá dar publicidade aos fatos denunciados. O Escola sem Partido garante 0 sigilo das informações capazes de permitir a identificação dos denunciantes e das vítimas, e se reserva o direito de não publicar as denúncias ou de publicá-las sem a identificação das pessoas ou instituições envolvidas. Apesar de não ser obrigatório, o preenchimento dos campos auxilia o nosso trabalho (ESCOLA SEM PARTIDO, 2020)

A Lei federal 12.527, de 18 de novembro de 2011, assegura o conhecimento das tratativas públicas, ressalvas, expressamente nela estabelecidas, ao mesmo tempo prevê no artigo 31, a indispensabilidade de respeito ao direito à privacidade, garantido pelo artigo 5ㅜㄹ inciso X, da Constituição Federal, portanto é necessário o diálogo pelos colegiados como conselho escolar, conselhos municipais, estadual e nacional de educação tomarem tal atitude, não um grupo expor em rede mundial pessoas por condutas ainda sem julgamentos. Afeta diretamente o direito de garantia da privacidade e guarda constitucional, ao definir a inviolabilidade da intimidade e da vida privada, bem como a imagem dos sujeitos, inclusive garantindo o direito a indenização 
por dano moral ou material em função da sua violação. A alegação é que todos devem saber as informações de cunho geral e de interesse coletivo, sob a vigilância da lei resguardados a segurança da sociedade e do Estado. E a escola possui assim como os sistemas municipais, estadual e federal órgãos colegiados para efetuar tais julgamentos e definir o que é público e o que é particular de direito inviolável do ser humano. A citação abaixo traz um depoimento em que acusam o que chama de doutrinação esquerdista no Colégio Loyola, de Belo Horizonte. Segue a descrição:

Na primeira semana de outubro/2019, uma professora de Língua Portuguesa do Colégio Loyola, em Belo Horizonte, aplicou uma prova aos alunos do $2^{0}$ ano do ensino médio, utilizando como base um texto de Gregório Duvivier. Diante do escancarado viés ideológico e político do texto, alguns pais reclamaram, e o colégio decidiu anular a prova, sem, todavia, explicar os motivos da decisão (...). O nome disso é doutrinação. Além disso, a virulência dos ataques a Bolsonaro, contidos no texto, cria um ambiente altamente propício ao bullying (ideológico e político) contra eventuais simpatizantes do presidente e do governo dentro da escola, gerando antagonismo e inimizade entre adolescentes que são obrigados a conviver no ambiente escolar. Isso é odioso por si só. Com efeito, o texto utilizado pela professora nada mais é do que uma peça de bullying contra bolsonaristas, o que é perfeitamente legítimo na imprensa, no rádio, nas redes sociais etc., mas não dentro de uma escola, onde a presença dos alunos é obrigatória (ESCOLA SEM PARTIDO, 2020).

Em seguida no site destaca como deve ser aulas do ensino fundamental e médio, fazem os apontamentos de forma arbitrária, ditatorial e antidemocrática além de evidenciar um tratamento vexatório. Descrevem em um cartaz, regras gerais do cotidiano escolar, como se todas as carreiras de formação, de cursos, de experiências não contassem mais, pois o que define a prática do professor é um simples cartaz que fere a autonomia docente.

Os argumentos do partido do PASP, são uma forma de olhar e interpretar a constituição federal a luz de retroceder o ensino, a escola a dimensões intangíveis e inimagináveis

Esses deveres já existem, pois decorrem da Constituição Federal e da Convenção Americana sobre Direitos Humanos. Isto significa que os professores já são obrigados a respeitá-los - embora muitos não o 
façam, sob pena de ofender: a liberdade de consciência e de crença e a liberdade de aprender dos alunos (art. 5, VI e VIII; e art. 206, II, da CF); o princípio constitucional da neutralidade política, ideológica e religiosa do Estado (Arts. 10, V; 5, caput; 14, caput; 17, caput; 19, 34, VII, 'a', e 37, caput, da CF); o pluralismo de ideias (art. 206, III, da CF); e o direito dos pais dos alunos sobre a educação religiosa e moral dos seus filhos (Convenção Americana sobre Direitos Humanos, art. 12, IV). Portanto, o único objetivo do Programa Escola sem Partido é informar e conscientizar os estudantes sobre os direitos que correspondem àqueles deveres, a fim de que eles mesmos possam exercer a defesa desses direitos, já que dentro das salas de aula ninguém mais poderá fazer isso por eles (ESCOLA SEM PARTIDO, 2020).

A atuação docente sempre foi respaldada em vida educativa, a qual deve estar em permanente formação, nas mais diferentes áreas do conhecimento, da didática, das metodologias, das técnicas, e que a ética docente permite o respeito e o ensino plural e de formação de sujeitos críticos.

A doutrinação política, como afirma a ideologia do partido do PASP, não passa pela cabeça do conjunto dos educadores. Sendo uma aberração um educador que estudou a vida inteira ter que ler e escrever sobre um jargão de tamanha deslealdade e maldade em relação a categoria. A formação ética profissional permite uma linha em que preserva a dignidade humana, o debate, político e religioso se caso questionado pelos educandos, o pluralismo de ideias e concepções, liberdade de ensinar, pesquisar aprender e o desenvolvimento critico dos estudantes em nível de exercer seu protagonismo na sociedade com possibilidade de escolhas.

O grupo ideológico, político do partido do PASP, justifica seus ideais, afirmando que professores utilizam livros, materiais didáticos para convencer os estudantes a serem militantes de esquerda. $O$ que traz também o debate religioso e de conduta moral, especialmente moral sexual. Por isso entendem ser urgente adotar medidas ideológicas contra as ideologias das quais eles são contra.

Segundo o PASP, eles querem seus filhos livres para seguir o que eles querem como seguir a consciência de crença segundo seus pais, contrariando o assegurado pelo art. 5ำ VI, da Constituição Federal, que compreende o direito do estudante a que o 
seu conhecimento da realidade não seja manipulado, para fins ideológicos e para fins de políticas partidárias.

O grupo do PASP considera o aluno uma tabula rasa em que tudo que o professor falar ele passivamente vai seguir feito um robô, principalmente quando afirmam que a audiência cativa dos alunos irá promover a religião e ideologias dos educadores. Não consideram professores educadores nem mesmo os estudantes como sujeitos críticos ao chamá-los de "Aluno: sem luz". A Liberdade de ensinar, assegurada pelo art. 206, II, da Constituição Federal - não anula a liberdade de consciência e de crença dos estudantes que possuem formação anterior a ida a escola e que estão se formando sujeitos autônomos, críticos e capazes de seguirem conforme suas vontades, não as de um grupo conservador e radical contra a esquerda.

$\mathrm{O}$ art. 5ำ do Estatuto da Criança e do Adolescente (ECA), assegura que nenhuma criança ou adolescente será objeto de qualquer forma de exploração, portando não pode ser considerado um sujeito cativo como afirma o grupo do PASP. Esse grupo visa criar um movimento de doutrinação conservadora, cristã e de ódio dentro das escolas, transformando os atos educativos em atos punitivos, atos de amor por atos de dor, atos de solidariedade por atos de denúncias, atos de doar por atos de tirar, atos de democracia por atos fascistas. O foco é a perseguição implacável de educadores de esquerda e críticos. Este grupo visa a posse irrestrita do estado para fazer ideologia conservadora. Ferindo desta forma a constituição federal em define o Estado como laico, deve manter uma posição de relação com todas as religiões, não pode usar o sistema de ensino para promover valores fascistas e conservadores.

O projeto afirma que vai gravar as aulas, caso a escola não o faça ou não disponibilize as gravações, o que fere a constituição. Não se pode usar imagens de crianças, como prevê o ECA. O artigo 53, par. único, do ECA, reconhece aos pais o direito de ter acesso e de conhecer, o projeto pedagógico da escola em que seu filho estuda. Por isso existe na escola, no município, nos estados e na união os conselhos amparados legalmente para serem os órgãos deliberativos de normativos da educação e permanentemente verificarem como está o ensino nas escolas e sistemas. 
Ao não aprovar esse projeto estamos de acordo com a Constituição, das leis e das instituições democráticas dentro das escolas e universidades, como determina o artigo 23, I, da Constituição; e no de "prevenir a ocorrência de ameaça ou violação dos direitos da criança e do adolescente", como prescreve o artigo 70 do Estatuto da Criança e do Adolescente.

\subsection{O PARTIDO DO PROJETO ESCOLA SEM PARTIDO - PASP}

Segundo Gramsci (2004), todo grupo social, nascendo no terreno originário de uma função essencial no mundo da produção econômica, cria para si, ao mesmo tempo, organicamente, uma ou mais camadas de intelectuais que lhe dão homogeneidade e consciência da própria função, não apenas no campo econômico, mas também no social e político, logo, os intelectuais de cada classe que representam têm a função de homogeneizar e conscientizar a classe da qual são orgânicos no campo social e político, de forma a garantir uma coesão e uma coerência com o campo econômico.

Ao mesmo tempo fica explicito que o partido pode estar diretamente associado a entidades, igrejas, doutrinas, grupos políticos, grupos organizados em função das questões econômicas.

Gramsci (2004) define o que é um partido, neste sentido podemos ver que muitas organizações autodenominadas "não-governamentais", "apartidárias", etc., na realidade funcionam como partidos políticos, pois visam organizar, educar e dirigir, tendo como princípio a formação dos dirigentes; assim os partidos podem se apresentar sob os nomes mais diversos, mesmo sob o nome de antipartido e de negação dos partidos. Seguindo esta linha de raciocínio, nosso autor diz que alguns partidos se apresentam como puramente educativos, moralistas, de cultura, no entanto "o partido é essencialmente político e até mesmo sua atividade cultural é atividade de política cultural" (GRAMSCI, 2004). Ou seja, "as organizações que buscam embelezar, camuflar, conquistar uma aparência positiva, neutra por meio de termos simpáticos como, por exemplo, cultura, são na realidade partidos - entendidos em seu sentido lato" (JURECÊ, 2019, p. 7). 
Reitera-se aqui o que já foi frisado por Saviani (2020), Moreira (2016) e Frigotto (2016), o Projeto do PASP quer, por meio de sua ideologia, estabelecer na educação pública, uma forma de educação sectária, parcial, moralista de pensamento de direita, conservador e religioso. Quando empiricamente buscamos na biografia dos autores do projeto, sem entrarmos em detalhes, notamos que ambos manifestam em seu cotidiano, são homens, brancos, de classe alta e média e com extremo apreço por partidos políticos de direita e religiões de cunho cristão e conservadoras. Isso já deixa explicito qual o partido e a ideologia do gueto da Escola Sem Partido. Ensino que prega que pensamentos e posicionamento de esquerda são pensamentos ideológicos, doutrinários, pela lógica isso quer dizer que todo pensamento que não é de esquerda não é ideológico. Qualquer manifestação religiosa, moral política deste que não seja de esquerda será aceita, isso pode abrir para pensamentos de estrema direita como foi o caso no nazismo de fascismo. Notoriamente na análise de discursos dos intelectuais do Escola Sem Partido notamos um desprezo pelo público e pela classe trabalhadora, muito mais ainda se esta sabe pensar e se posiciona como sujeito na sociedade.

\section{CONSIDERAÇÕES FINAIS}

Notoriamente existe um desprezo pelo pobre, pelo imigrante, pelo indígena, pelo quilombola, pelo negro, porque em seus discursos e leis tudo é genérico, não leva em consideração a diversidade de sujeitos que residem no país. Existe sim um cunho raivoso no sentido de preservar uma educação morta, sem vida, sem debate, sem criticidade, sem direito a escolha, sem direito a diálogo, em nome de uma falsa neutralidade que não existe de forma alguma, nem na filosofia nem na sociologia muito menos na sociedade em geral. O que existe são mecanismos políticos de organização da sociedade com é caso da legislação que prevê os princípios de democracia, liberdade, autonomia, igualdade e ética no respeito a pluralidade da vida, das ideias e que possibilita aos cidadãos um convívio harmonioso mesmo com pensamentos e ações distintas. O contrário disso é fascismo. Esse projeto de cunho moral, visa ser moralista, e interferir no processo de desenvolvimento humano, desconsiderando milhares de anos de avanços da humanidade e da ciência no qual a escola apenas 
utiliza para ampliar os horizontes de conhecimento em que os cidadãos possam ter a escolha e o livre arbítrio em relação a sua vida. No que concerne aos objetivos de aprendizagem e ensino, as demandas conservadoras podem ser resumidas, sem prejuízo dos argumentos levantados, em alguns pontos. Na página do ESP a defesa dessas demandas é subsidiada por um conjunto de exemplos de uma suposta doutrinação produzida via currículo, com o apoio de uma suposta burocracia do Ministério da Educação e das secretarias de educação, assim como dos meios de comunicação. Os elementos cruciais para os ideólogos da ideologia da Escola Sem partido estão na divisão entre público e privado passando para a família a obrigatoriedade da formação ética e moral. A escola apenas para levar conteúdos frios, pragmáticos e sem relação com a realidade. Contra qualquer manifestação considerada de cunho ideológico de esquerda, contra a diversidade cultural nos currículos e contra a ideologia de gênero nos currículos.

Na prática evidenciamos que não existe neutralidade na fala dos ideólogos do PASP, nesse sentido, a Escola sem Partido não é neutra e apartidária, pelo contrário, tratase de um único partido: da intolerância com um grau acentuado de preconceito em relação as questões de gênero, etnia, pobreza.

A neutralidade na educação é apenas um discurso para poder convencer a sociedade. Compreende-se a posição do PASP da defesa das ideologias da política de extrema direita, de caráter religioso conservador e contrário as políticas sociais de esquerda.

Em tempo, para não cairmos na ingenuidade dos moralismos do referido projeto ESP, podemos afirmar que existe uma linearidade ideológica do PASP com o neoliberalismo. O capital sempre está atrelado aos projetos de desenvolvimento educacional dos países pobres em desenvolvimento, e não seria diferente neste. Pois a característica principal dos projetos economicistas do capital é retirar a dimensão do político dos projetos educacionais, o que casa direitinho com o PESP.

O PESP está alicerçado dentro de uma lógica neoliberal. O que caracteriza a normatividade neoliberal é a submissão do Estado, ao plano de crescimento econômico, ao posicionamento competitivo e ao aumento do capital. A especificidade 
do neoliberalismo é que os homens e mulheres estão inseridos em um modelo único de capital financeiro e de investimento, sem necessidade de homens e mulheres políticos, críticos e polidos e, portanto, sem a necessidade de mudanças sociais.

Portanto o que prevalece são interesses hegemônicos conduzidos pelo capital, em detrimento do valor do humano. Neste aspecto seriamos ingênuos, imaginar que eles pensem na escola como os educadores e educadoras pensam: escola como lugar de socialização, produção, apropriação do conhecimento e formação integral do ser humano, visando a transformação da realidade para um mundo mais democrático, humano e justo.

\section{REFERÊNCIAS}

BROWN, W. Undoing the demos: Neoliberalism's stealth revolution.New York: Zone Books, 2015.

ESCOLA SEM PARTIDO. Doutrinação pelo mundo. Disponível em: http:// www.escolasempartido.org/doutrinacao-pelo-mundo. Acesso em: 24/06/2019.

ESCOLA SEM PARTIDO. Por uma lei contra o abuso da liberdade de ensinar. Disponível em: https://www.programaescolasempartido.org/. Acesso em 10/01/2020.

FOUCAULT, M. A ordem do discurso. 4. ed. São Paulo: Loyola, 1998.

FRIGOTTO, G. Imposição da Mordaça aos Educadores. e-Mosaicos. Rio de Janeiro: v. 5, n. 9, p. 11-13, jun. 2016.

GRAMSCI, A. Cadernos do cárcere. V. 2. 3를 ed. Rio de Janeiro: Civilização Brasileira, 2004.

JURUCÉ, R. O partido político para Antonio Gramsci: o papel histórico dos intelectuais e dos aparelhos de hegemonia. Disponível em: https://pcb.org.br/portal/precongresso/juruce.pdf. Acesso em: 11/02/2020. 
MACEDO, E. As demandas conservadoras do movimento escola sem partido e a base nacional curricular comum. Educ. Soc. Campinas, v. 38, ํ․ 139, p.507-524, abr.-jun., 2017.

MOREIRA, A. "Escolas sem partido" ou Pensamento Único?Disponível em:https://aluiziomoreira.blogspot.com. Acesso em 01/09/2020.

OLIVEIRA, A. C.; LANZA, F.; STORTO, L. J. A educação básica brasileira em disputa: doutrinação versus neutralidade. Revista Katál. Florianópolis, v. 22, n. 3, p. 468-478, set./dez. 2019 ISSN 1982-0259.

PEREIRA, L. C. Movimento Escola sem Partido. Disponível em: https://www.infoescola.com/educacao/escola-sem-partido/. Acesso em: 05/02/2020.

SAVIANI, D. Escola sem Partido: o que isso significa? Disponível em: http://lucianasantos65.com.br/dermerval-saviani-escola-sem-partido-o-que-issosignifica/. Acesso em 01/09/2020.

\section{APÊNDICE - REFERÊNCIA DE NOTA DE RODAPÉ}

2. Disponível em: http://www.escolasempartido.org/. Acesso em 10 de jul. 2020.

Enviado: Agosto, 2020.

Aprovado: Outubro, 2020. 